\title{
Use of Social Networking Sites and Other Services for Learning among College Youth
}

\author{
Mool Raj, Adit Gupta, and Nidhi Slathia
}

\section{ABSTRACT}

Most of the college youth believe that the social networking sites and other streaming services facilitate the learning process. The purpose of the present research study was to assess the attitudes of college youth towards social networking sites and utilising other services such as YouTube etc. as tools for education. The sample for the study were selected randomly and included 180 college youth studying in Government Degree colleges of Jammu, India. Data were collected through survey method and self-prepared tool which was used to assess the attitude of college youth towards social networking sites and other services as a tool for education. Findings revealed that YouTube is used by a large number of users as compared to WhatsApp and Facebook. Majority of the undergraduate youth are using YouTube videos, WhatsApp messenger and LinkedIn for viewing and sharing educational content. It was also found that male college youth used more of LinkedIn and Twitter, while female college youth used more of Facebook, WhatsApp and YouTube. In addition to this, the study shows that no significant differences exist in the attitude and perceived impact of male and female students at the undergraduate level. However, they have equally shown positive and favourable attitude towards social networking.

Keywords: social networking, tools for learning, college youth, attitude, impact

Published Online: March 29, 2021

ISSN: $2736-4534$

DOI :10.24018/ejedu.2021.2.2.59

Mool Raj

MIER College of Education, India

(e-mail: moolraj.sharma ${ }^{@}$ miercollege.in)

Adit Gupta

MIER College of Education, India

(e-mail: adit@mier.in)

Nidhi Slathia

MIER College of Education, India

(e-mail: nidhi.jamwal@miercollege.in)

\section{INTRODUCTION}

The prime function of education is to draw out the potentialities of the child and develop them to meet the challenging situations of life. The last half a century has witnessed a phenomenal growth in the development and application of various information technologies in the field of education. Information technology is the application of computers to store, retrieve, transmit and manipulate data, often in the context of a business or other enterprise. The use of social networking by students, teachers and institutions has opened up a great opportunity for educational research and enhancing the teaching-learning processes. Nowadays, individuals are participating in a variety of activities from consuming content to sharing knowledge, experience, opinions, and are involved in discussion with others. Today, with the growth of internet, online social networking websites, instant messaging and video streaming services have become important communication channels for teachers and students. The growth of online social networking websites and other services such as, Facebook, Twitter, LinkedIn, Google+, WhatsApp, and YouTube etc. have thrown open new vistas for the promotion of educational content. One can say that Facebook is one of the most popular social networking sites. Social networking sites are being used as pedagogical tools as students and teachers can use them for connectivity, social support, collaborating on information gathering, discovery and sharing, content creation, aggregation and modification of information (Ansari \& Khan, 2020). Today, with the growth of internet, online social networking websites have become important communication channels and virtual communities have emerged. Groups may never meet in the physical world but they are able to affect behaviour including purchasing decisions through social networking websites (Evans, et al., 2009).

Attitude plays a key role in achieving successful social interaction among teachers and students and wins their attention in favour of the required educational modality. Anastasi (1957) defines attitudes as a tendency to react in a certain way towards a designed class of stimuli. Many attitudes are the result of deliberately planned education and religious training and influences and propaganda. Person oriented teachers are likely to enjoy their contacts with students and to hold generally favourable attitudes towards them. Teacher's attitudes can affect teacher student interactions. Thus, attitudes have the potential for affecting students and for functioning as self-fulfilling prophecies (Gentrup, et al., 2020). On the other hand, it is very important to know the impact of any innovation on our lives, so the perception regarding the use of social networking is also important for the betterment of our educational system 
especially our students.

Today in India particularly among the Indian college students, the usage of social networking sites has significantly increased (Kapoor et al., 2018) and it certainly has farreaching impact on the academic and other activities of the students. The range of studies conducted to deal with the use of social networking among college students is increasing day by day. In general, college students are more interested in using advanced technology in every field as compared to any other age group. Some studies on social networking tools shows that it can improve the learning experience while other studies reveal that high use of social media results in negative academic outcomes. Students of the current generation have been exposed to a technology rich world that has led them to become dependent on social media as a means for communication.

Social networking sites have rapidly gained popularity. The usage of social networking sites among the people of India is evidently increasing, particularly among the Indian college students (Lavanya \& Karthikeyan, 2016). As the use of technology and social media became more prevalent, educators and parents alike wanted to keep it out of the classroom for fear that it would be too distracting. This led to many schools blocking internet access, access to social media sites, and even disallowing the use of, or even the bringing of cell phones to class. This has proved to be ineffective in some cases, as students continue to bring their phones to class despite the no cell phone policy, and many even find ways to access social media sites regardless of precautions taken by educational administrators. Rather than compete with, or deny access to social media sites, some institutions have totally embraced them, and are using them to further students' education.

Learning is the process of acquiring or modification in a behavioural tendency by experience in contrast to modification occurring because of development or a temporary physiological condition of the organism. The study of social networking within a learning domain encompasses the processes of social learning that occur when a selfselecting group of people who have common interest in a subject collaborate to share and idea to find solution to a problem. Critics argue that the average student learning in isolation performs significantly less than those learning with collaboration (Croft, et al., 2010).

\section{OBJECTIVES OF THE STUDY}

The objectives for the study are as follows:

1) To compare the extent of use of social networking sites and other services for learning by male and female college youth at the undergraduate level.

2) To compare the social media habits of male and female college youth at the undergraduate level.

3) To investigate gender difference in attitude towards learning through social networking sites and other services among college youth at the undergraduate level.

4) To investigate gender differences in perceived impact of social networking sites and other services on learning by male and female college youth.

\section{METHODOLOGY AND DESIGN}

\section{A. Sample}

A sample of 180 college students studying at the undergraduate level and using social networking sites and other services for education were selected for the present study. The sample comprised of randomly selected 30 male and 30 female college youth each studying in Bachelor of Education (B. Ed.), Bachelor of Science (B. Sc.) and Bachelor of Commerce (B. Com.) classes in each college respectively.

\section{B. Method}

Descriptive survey method was adopted to study the use of social networking sites and other services by male and female college youth at the undergraduate level.

\section{Tool Used}

A self-prepared tool was used for studying the use of social networking sites and other services by college youth at the undergraduate level. The tool comprised of 50 items. The first five items were related to social media habits, next 24 items were related to attitude towards social networking and the last 21 items were related to perceived impact of social networking on learning by college youth at the undergraduate level.

\section{RESULTS AND FINDINGS}

The responses given by college youth were analysed through statistical package and frequencies and percentage were computed on all items of questionnaires. Major findings of the present study are reported in the following subsections. The first part of the results and findings throws light on the social media habits and extent of use of social networking sites and other services for learning by male and female college youth at the undergraduate level and the last part presents the results for significant differences.

\section{A. Use of Social Networking Sites and Other Services}

Percentage of responses for using social networking sites and other services by college youth at the undergraduate level have been given in Figure 1.

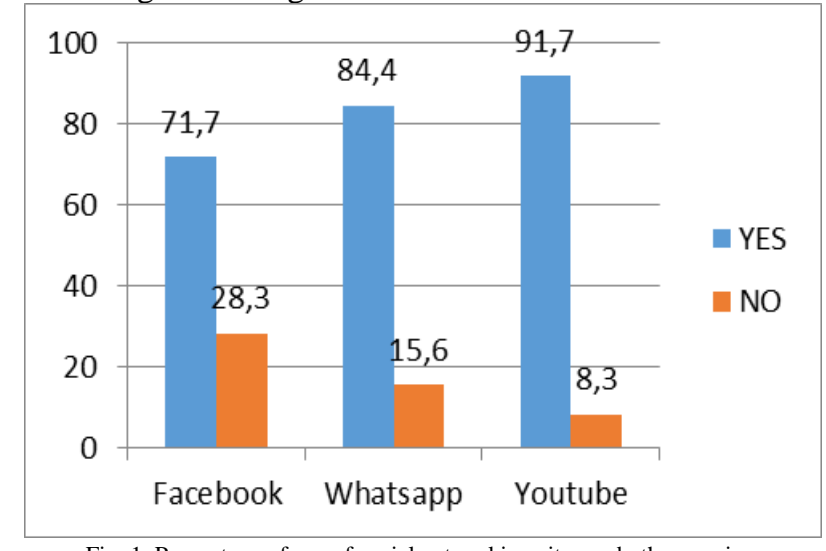

Fig. 1. Percentage of use of social networking sites and other services

Figure 1 shows that out of 180 undergraduate youth, $71.7 \%$ have responded that they use Facebook. Similarly, 84.4\% college youth have responded that they use WhatsApp and for YouTube usage, the percentage of college youth is $91.7 \%$. It can be seen that highest number of youth $(91.7 \%)$ uses YouTube, $84.4 \%$ uses WhatsApp and lowest percentage (71.7\%) uses Facebook. This implies that YouTube which is a video streaming and sharing service is being used by a 
larger number of users as compared to WhatsApp and Facebook for educational purposes.

\section{B. Extent of Use of Social Networking Sites and Other Services for Educational Purposes}

To know the extent of use of social networking sites and other services, responses of the participants were converted into percentages and Figure 2 depicts the extent of use of Facebook, WhatsApp, LinkedIn, Twitter and YouTube by college youth at the undergraduate level.

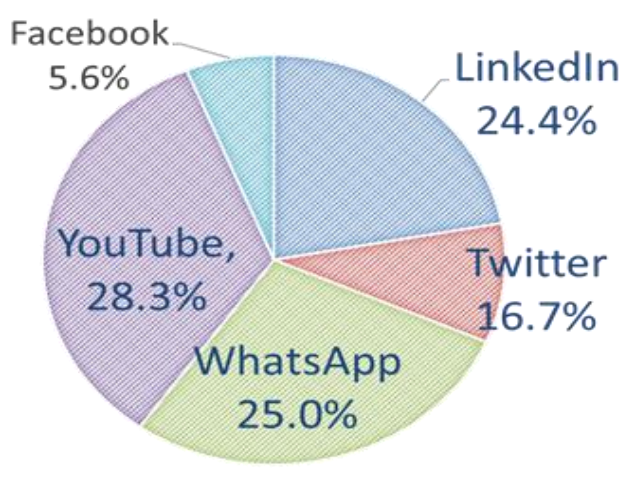

Fig. 2. Percetage of extent of use of social networking sites and other services for educational purposes

Figure 2 depicts that $28.3 \%$ of youth studying in the undergraduate colleges are using YouTube, $25 \%$ are using WhatsApp, $24.4 \%$ are using LinkedIn, 16.7\% are using Twitter and $5.6 \%$ of the youth are using Facebook for educational purposes only. This implies that undergraduate youth are mainly using YouTube video streaming and sharing services, WhatsApp messaging and LinkedIn social networking sites for viewing and sharing educational matter.

\section{Gender Comparison of the Use of Social Media and Other Services for Learning Purpose}

Percentage of responses for using social networking sites and other services for learning by female and male college youth at the undergraduate level have been depicted in Figure 3.

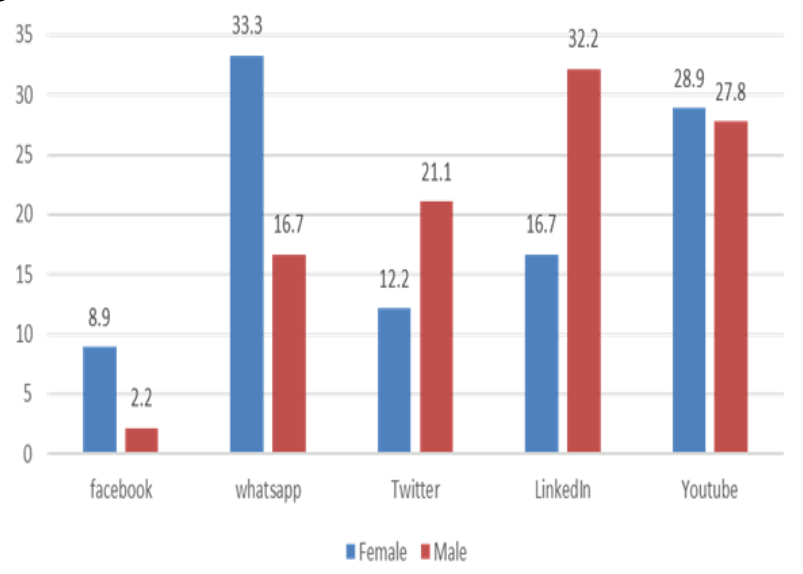

Fig. 3. Comparision of responses for most used social networking sites and other services by male and female undergraduate students

Data in Figure 3 reveals that out of 90 female youth, $8.9 \%$ female used Facebook, 33.3\% used WhatsApp, 12.2\% used Twitter, $16.7 \%$ used LinkedIn, and rthe emaining $28.9 \%$ used YouTube for learning purposes. Results also revealed that out of 90 male youth, 2.2\% males used Facebook, $16.7 \%$ used WhatsApp, $21.2 \%$ used Twitter, 32.2\% used LinkedIn, and remaining 27.8\% used YouTube for learning purposes. This implies that female college youth use more WhatsApp, YouTube and Facebook for learning in comparison to male college youth at the undergraduate level, who on the other hand used more LinkedIn, YouTube and Twitter as compared to female youth at the undergraduate level. A large number of female youth use WhatsApp while male youth use LinkenIn. Both use YouTube to a similar extent and Facebook is used for learning by less number of youth irrespective of their gender.

\section{Number of Hours Spent for Browsing Social Networking Sites and other Services for Education Purposes}

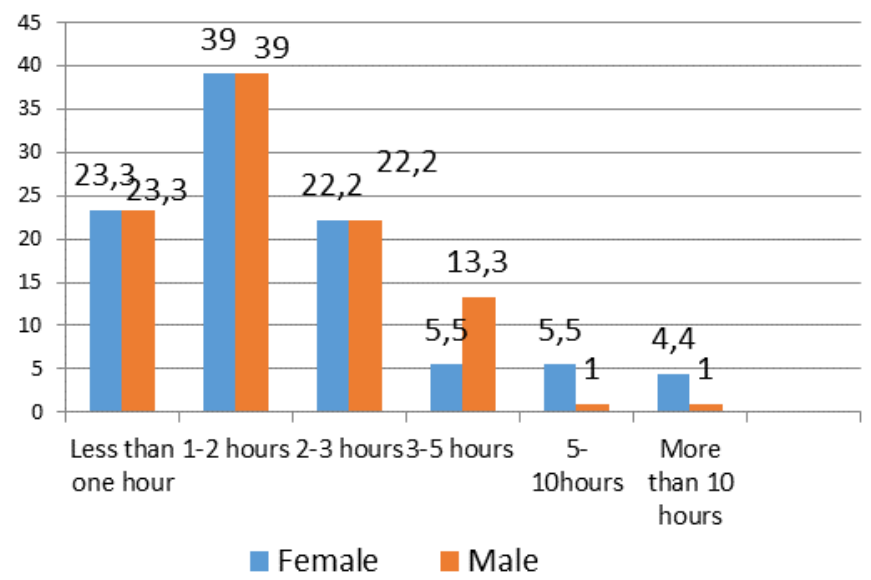

Fig. 4. Number of Hours Spent on Social Networking Sites and other Services

Data in Figure 4 reveals that $23.3 \%$ of both female and male undergraduate youth have spent less than 1 hour in a day on social networking sites and other services. However, 39\% of both groups of undergraduate youth have responded that they spent 1-2 hours on social networking sites, same percentage i.e. $22.2 \%$ of both female and male undergraduate youth spend 2-3 hours on social networking sites and use other services. Also, $5.5 \%$ of female and $13.3 \%$ of male college youth have responded that they spent 3-5 hours on social networking sites, $5.5 \%$ female and $1 \%$ male college youth have responded that they spent $5-10$ hours on social networking sites and $4.4 \%$ female and $1 \%$ male college youth have responded that they spent more than 6 hours on social networking sites and using other services for educational purposes. So, it can be seen that both male and female youth at undergraduate level spend enough time in browsing social networking sites and other services.

E. Gender Differences in Attitude Towards Learning through Social Networking and Other Services Among College Youth at the Undergraduate Level

Data in Table 1 shows that the mean value of attitude of female college youth towards using social networking and other services is 81.38 and the mean value of attitude of males is 81.40 . The value of ' $t$ ' $(0.89)$ is not significant and hence no significant differences in attitude of males and females towards learning through social networking sites and other services were found to exist. However, both the groups (male and female) have equally shown positive and favourable attitude towards social networking sites and other services as the mean score is more than 72 for 24 items on a five point scale. 
TABLE I:

Mean, Standard Deviation and t- value for Attitude of College Youth at the Undergraduate Level Towards Social Networking Sites and Other

\begin{tabular}{|c|c|c|c|c|c|c|c|}
\hline Gender & $\mathrm{N}$ & Mean & SD & SEM & df & $\mathrm{t}$ & Sig. \\
\hline Female & 90 & 81.38 & 8.23 & 0.87 & \multirow{2}{*}{178} & \multirow{2}{*}{0.89} & N.S \\
\hline Male & 90 & 81.40 & 6.48 & 0.68 & & & \\
\hline
\end{tabular}

\section{F. Gender Differences in Perceived Impact of Social Networking Sites and Other Services on Learning by College Youth at the Undergraduate Level}

TABLE II:

Mean, Standard deviation and t-value for Male and Female on Perceived

\begin{tabular}{|l|l|l|l|l|l|l|l|}
\hline \multicolumn{1}{|l|}{ Impact of Social Networking Sites and Other Services. } \\
\cline { 1 - 6 } Female & 90 & 22.42 & 3.60 & 0.38 & \multirow{2}{*}{178} & 0.69 & N.S \\
\hline Male & 90 & 22.80 & 3.73 & 0.39 & & & Sig. \\
\hline
\end{tabular}

The computed value of ' $t$ ' $(0.69)$ as shown in Table II is not significant and it indicates that there is no difference in the impact scores obtained on social networking sites and other services by males and females college youth for learning purposes. However, both the groups (male and female) have obtained average level of impact scores on social networking sites and other services and it can be said that male and female college youth have perceived positive and favourable impact of social networking on them as the mean score obtained is more than 21 for a 21 items scale.

\section{CONCLUSIONS}

Based on the interpretation of the results drawn in the present study as discussed in previous chapter, the investigator lays down the following conclusions:

1) YouTube video streaming and sharing service is used by a larger number of undergraduate college youth than WhatsApp and Facebook.

2) Undergraduate college youth use YouTube, WhatsApp and LinkedIn to a greater extent that other social networking sites and services for learning purposes.

3) Female college youth use more WhatsApp, YouTube and Facebook for learning in comparison to male college youth at undergraduate level, who on the other hand use more LinkedIn, YouTube and Twitter than their counterparts.

4) Results revealed that they spend enough time in browsing for educational content on social networking sites and using other services such as YouTube etc. About $85 \%$ of both female and male undergraduate youth spend less than 2-3 hours per day on social networking sites.

5) The present study revealed that, there are no gender differences in the attitudes and perceived impact of college youth at the undergraduate level towards social networking sites and other services being used for educational purposes. However, they have shown positive and favourable attitudes and impact of social networking sites on their studies.

Hence, it can be said that both male and female college youth at the undergraduate level are using social networking sites. For browsing social networking sites, they are using devices according their own convenience and availability.

They are using these websites for educational purposes and they $\log$ in very frequently on these websites for their studies. They have positive and favourable attitude towards learning through social networking sites at the undergraduate level and they have perceived its positive impact on their studies.

\section{REFERENCES}

Akyildiz, M., \& Argan, M. (2011). Using online social networking: students' purposes of facebook usage at the university of Turkey. Journal of Technology Research, 1, 1-11.

Ansari, J. A. N., \& Khan, N. A. (2020). Exploring the role of social media in collaborative learning the new domain of learning. Smart Learn. Environ. 7, 9 https://doi.org/10.1186/s40561-020-00118-7.

Banguil, K., Chua, N. A., Leano, G.A., Riverso, M.A., C. A., Bruce, Dianalan, S.A., Matinezo, A.R., \& Timog, N. U. (2009). Social networking sites affect one's academic performance adversely. Retrieved on January 18, 2020 from http://www. Scribed. Com/doc/ 28919575/ SOCIAL-NETWORKING-SITE S-2009

Brydolf, C. (2007). Minding MySpace: Balancing the benefits and risks of students' online social networks. Education Digest, 73(2), 4.

Coyle, C. L., \& Vaughn, H. (2008). Social networking: Communication revolution or evolution? Bell Labs Technical Journal, 13(2), 13-17.

Dhiraj, M. (2013). Twitter: Social Communication in the Twitter Age. Cambridge, UK: Polity Press, 193 pp.

Eberhardt, D. (2006). The Facebook My space era: A help or hindrance to college students and administrators'? Journal of College \& Character, 7(7), 1-2

Folorunso, O. (2010). Diffusion of innovation in social networking site among university students. International Journal of Computer Science and Security, 4 (3), 361-372.

Jasmeane. (April, 2015). Education is the key to success by scholarship essay. $\quad$ Retrieved from https://www.varsitytutors.com/scholarship_entries/jasmeane-5617.

John, H., Heinrichs, J. L., \& Kee-Sook, L.( 2011). Influence of social networking site and user access method on social media evaluation. Journal of Consumer Behaviour, 10 (6), 347-355.

Juang, Y.R. (2010). Integrating social networking site into teaching and learning. In S.L Wong proceedings of the 18th International conference on computers in education (p 244-251) Putrajaya, Malaysia: AsiaPacifies society for computers in Education.

Kapoor, K.K., Tamilmani, K., \& Rana, N.P. (2018). Advances in social media research: Past, present and future. Information Systems Frontiers, 20, 531-558. https://doi.org/10.1007/s10796-017-9810-y.

Kevin, P. B., Lori B. H., \& Bethany, V. S. (2010). The use of alternative social networking sites in higher educational settings: A case study of the e-learning benefits of ning in education. Journal of Interactive Online Learning, 9(2), 151-170.

Kuppuswamy, S., \& Narayan, P. B. S. (2010). The impact of social networking websites on the education of youth. International Journal of Virtual Communities and Social Networking, 2(1), 67-79.

Lavanya, R., \& Karthikeyan, P. (2016). A study on the usage of social networking sites among college students with reference to Erode District. Asian Journal of Research in Social Sciences and Humanities 6(6):1230. DOI: $10.5958 / 2249-7315.2016 .00280 . \mathrm{X}$

Peluchette, J., \& Karl, K. (2008). Social networking profiles: An examination of student attitudes regarding use and appropriateness of content Cyberpsychology and Behaviour, 11 (1), 95-97.

Pempek, T. A., \& Calvert, S. L. (2009). College students' social networking experiences on facebook. Journal of Applied Developmental Psychology, 30, 227-238.

Salvation, M., \& Adzharuddin, N.A. (2014). The influence of social network sites upon academic performance of Malaysian students. International Journal of Humanities and Social Science, 14(10).

Subramani, R. (2015). The academic usage of social networking sited by the university students of Tamil Nadu. Online Journal of Communication and Media Technologies, 5 (3), 162-175.

Tiryakioglu, F., \& Erzurum, F. (2011). Use of social networks as an education tool. Contemporary Educational Technology, 2 (2), 135-150. 